\title{
Thermodynamic Modelling of Petroleum Fluids
}

\author{
J.C. de Hemptinne ${ }^{1}$ and E. Béhar ${ }^{1}$ \\ 1 Institut français du pétrole, 1 et 4, a venue de Bois-Préau, 92852 Rueil-M almaison Cedex - France \\ email: j-charles.de-hemptinne@ifp.fr - emmanuel.behar@wanadoo.fr
}

\begin{abstract}
Résumé - Modélisation thermodynamique des fluides pétroliers - Les développements récents et les défis nouveaux de la thermodynamique pétrolière sont présentés dans les articles de ce numéro spécial de «Oil and Gas Science and Technology» (OGST). Un des objectifs, commun à ces travaux de recherche, est la mise à disposition d'outils de calcul qui doivent permettre à des simulateurs des métiers pétroliers d'avoir accès à des propriétés thermodynamiques et thermophysiques fiables. Le présent article propose, en guise d'introduction, de mettre ces développements dans une perspective plus large, en suggérant un cadre dans lequel l'ingénieur métier pourra trouver un guide pour la sélection de la ou des méthodes les plus adaptées à son problème.

L'analyse est basée sur l'observation que deux éléments essentiels doivent être réunis pour une bonne modélisation des propriétés physiques des fluides naturels complexes (pétroles bruts et gaz à condensat): un modèle (équation d'état et règles de mélange) qui représente au mieux la réalité physique et une description compositionnelle adaptée.

Un modèle est défini comme un ensemble d'équations mathématiques décrivant les relations qui peuvent exister entre différentes propriétés. Certains sont empiriques, d'autres sont construits sur des concepts physiques, avec plus ou moins d'approximations. Tous contiennent des paramètres qui devront être déterminés et validés à l'aide de données expérimentales. Si la précision des résultats est importante, il est essentiel d'utiliser une sélection de données fiables. Au contraire, si on recherche plutôt un modèle prédictif (peu ou pas de données sont disponibles), on préférera utiliser un modèle dont la conception physique est solide.

La composition moléculaire des fluides pétroliers est souvent inconnue ; et même si elle était connue, elle contiendrait tant d'isomères qu'une description détaillée serait ingérable dans un simulateur à «vocation métier». De nombreuses méthodes ont été développées pour contourner ce problème. Les méthodes habituelles sont de type corrélatif, mais nous pensons qu'elles ont atteint leurs limites. De nouvelles méthodes, dont la simulation moléculaire, sont sans doute plus prometteuses.

En conclusion, nous estimons qu'une compréhension plus approfondie des phénomènes physiques par le biais des outils expérimentaux est essentielle, afin de permettre ensuite le développement de modèles plus fondamentaux, ayant de meilleures performances en pouvoir prédictif et en terme de précision. Tels sont les défis que la thermodynamique moderne doit relever. Les articles publiés dans ce recueil en illustrent quelques exemples.
\end{abstract}

Abstract - Thermodynamic Modelling of Petroleum Fluids - The recent developments and challenges of petroleum thermodynamics are presented in the various papers of this special issue of Oil and Gas Science and Technology (OGST). A common objective of these investigations is the development of calculation tools providing access to reliable thermodynamic as well as thermophysical properties. Hence, this introductory article attempts to put these new developments in a larger perspective by proposing a framework where the practicing engineer can also find some guidelines 
for the selection, among the large number of existing methods, of the one(s) most suited to his/her industrial application.

The analysis is based on the observation that two main features must be present for a good representation of the physical behaviour of complex natural fluids: a model (equation of state - eos- and mixing rules) that represents the physics as well as possible, and an appropriate compositional description.

A model is defined as a set of mathematical equations that describes the relationships among different properties. Some are empirical, others are constructed on a physical basis with more or less approximations. All contain parameters that must be determined and validated using experimental data. When accurate properties are required, it is important to focus on the selection of reliable data. However, when predictive power is required (few or no data are available), the use of a model that has a strong physical foundation is essential.

The detailed molecular description of a petroleum fluid is often unknown, but even if it were known, it would contain so many isomers that it would be very difficult to handle in an engineering simulator. Hence, several methods are employed to circumvent the problem. The traditional methods are correlations, but we believe they are reaching their limit. New methods, among which molecular simulation, are probably more promising.

As a conclusion, we state that both an improved understanding of the physics through experimentation, and an increased use of these physical findings in new models, are the challenges for the future developments of thermodynamics. The papers in this issue illustrate a number of such developments.

\section{LST OF SYMBO LS}

Symbol Meaning

\section{Latin Letters}

$c_{p} \quad$ heat capacity at constant pressure

$k_{i j} \quad$ binary interaction parameter

$v^{\text {Liq }} \quad$ liquid molar volume

$v \quad$ molar volume

$x$

\section{Latin Capitals}

$\begin{array}{ll}G^{E} & \text { excess Gibbs energy } \\ H^{E} & \text { excess enthalpy } \\ K_{i} & \text { partition (equilibrium) coefficient } \\ P & \text { absolute pressure } \\ \wp & \text { Poynting correction } \\ T & \text { absolute temperature } \\ Z & \text { compressibility factor ( }=P V / N R T= \\ M W & \text { Molecular Weight } \\ \text { G reek } & \text { Letters } \\ \gamma & \text { activity coefficient in a liquid phase } \\ \varphi & \text { fugacity coefficient } \\ \omega & \text { acentric factor }\end{array}$

\section{Subscripts}

$\begin{array}{ll}c & \text { critical parameter } \\ i & \text { component index in a mixture } \\ b & \text { value at the boiling point }\end{array}$

\section{Superscripts}

$\mathrm{m}^{3} / \mathrm{kmol} \quad$ \# ideal gas state

$\mathrm{m}^{3} / \mathrm{kmol} \quad L \quad$ liquid phase property

$V \quad$ vapour phase property

$\sigma \quad$ saturation property

\begin{tabular}{lll}
$\mathrm{J} / \mathrm{K} / \mathrm{kmol}$ & \multicolumn{2}{l}{ Superscripts } \\
- & $\#$ & ideal gas state \\
$\mathrm{m}^{3} / \mathrm{kmol}$ & $\#$ & liquid phase property \\
$\mathrm{m}^{3} / \mathrm{kmol}$ & $L$ & vapour phase property \\
- & $V$ & saturation property \\
- & $\sigma$ &
\end{tabular}

Abbreviations

J

$\mathrm{J}$

$\mathrm{Pa}$

$\mathrm{K}$

$\mathrm{kg} / \mathrm{mol}$

eos equation of state
BIP Binary Interaction Parameter

CCE Constant Composition Expansion

CVD Constant Volume Depletion

DIPPR Design Institute for Physical PRoperties, AIChE (databook with evaluated thermophysical property data)

$C P A \quad$ Cubic Plus Association equation of state

$P R \quad$ Peng-Robinson equation of state

$P R H \quad$ Peng-Robinson equation of state with the HuronVidal mixing rule

MHV2 Modified Huron-Vidal mixing rule (of the 2nd order)

NRTL Non Random Two Liquids GE model (Renon \& Prausnitz, 1968)

SAFT Self-Associating Fluid Theory equation of state

$S R K \quad$ Soave-Redlich-Kwong equation of state 


\section{IN TRO DUCTION}

The thermodynamic properties of petroleum fluids have been successfully described for many years. However, a continuous effort for improving this modelling is necessary because of the more stringent requirements on the processes. We observe an ever increasing need in accuracy, in predictive power (i.e. in the absence of data), and a shift towards systems with a larger non-ideal behaviour (polar components and/or having a hydrogen bonding potential), including reactive systems.

The driving power for present industrial needs is improving fossil fuels recovery and transforming them into gasoline and gasoil with the help of environmentally friendly processes, thus leading to a sustainable development of the oil and gas industries.

In the upstream industry, reservoirs containing high levels of acid gases are being more exploited. In addition, newly explored deep buried reservoirs have much higher pressures and temperatures than those usually met in the past. Finally, as a result of the present interest for reservoirs containing heavy crudes, or due to offshore conditions (high pressures associated with low temperatures), the risk of solid deposits related to asphaltenes, paraffins or hydrates has to be considered more often.

In the downstream industry, we observe several types of evolutions: the stringent reduction of harmful components (sulfur containing molecules, aromatics, etc.) in gasolines and gasoils proposed to the end-users; the deeper hydroconversion of heavy fractions into such fuels at higher temperatures in presence of hydrogen. In addition, the use of biofuels will require an improved understanding of the behaviour of mixtures containing polar components.

This journal issue wants to focus on the main challenges involved in today's description of the thermodynamic properties of petroleum fluids. The four subsequent papers in this issue can be classified as two application examples where new approaches are to be developed and two modelling techniques that are increasingly used in the petroleum industry. The applications are gas treatment and asphaltenes deposition.

- Gas treatment techniques (acid gases removal) require both physical absorption in strongly non-ideal conditions (vapour-liquid equilibria) and chemical transformation in the aqueous phase. At present, the only way to describe the physics is to combine several empirical approaches, based on a large number of experimental data.

- Asphaltenes deposition occurs in many instances in the petroleum chain. The composition of these heavy petroleum fractions is very badly known, and even the physical phenomenon at hand during flocculation is still subject of strong debate (liquid - liquid equilibrium, liquid - solid equilibrium or micelle formation?).
Both of these examples clearly illustrate the limits of the classical thermodynamic methods. Yet, the ever increasing number of fundamental data along with the rapid increase of computer power makes it possible to understand the microstructure of "simple" fluids, thus allowing the development of new tools that will lastingly affect the way thermodynamic properties are predicted. In the two subsequent papers of this issue, these tools are further enlightened:

- Molecular simulation (see also Ungerer et al., 2005) is a technique that has now come out of infancy, as it allows the calculation of increasingly complex systems with a rather high degree of accuracy. It can now be considered as a true alternative to experimental approaches for systems of interest to the petroleum industry.

- New equations of state based on statistical mechanics have developed as a consequence of the information made accessible through molecular modelling. Based on their physical foundation, these new equations are capable of extrapolating far beyond what could be expected from classical, semi-empirical, models. Some examples are provided in a paper of this issue.

We believe that the challenges that are discussed in these articles can be classified in two main topics. Each of these will be discussed in a separate section of the present paper:

- The first is related to the model that is used. From purely empirical correlations to very complex equations based on statistical thermodynamics or molecular simulation approaches, a large range of tools has been developed in the last century. Even though many equations are no longer in use, a number of them that are rather ancient, are still used in modern computing tools.

- The parameters required in the above models generally originate from databases, or are calculated using independent correlations (e.g. group contributions, etc.) or are fitted to experimental data. Petroleum fluids have the particularity that their molecular composition is badly known. As a result, several empirical methods are used in order to build the best possible analytical representation. These will be discussed in a second section.

These two topics must be handled by the practicing engineer who uses his simulator toolbox in order to describe the physical behaviour of a produced or a processed fluid. The additional objective of this paper is to provide him with some guidelines for selecting the thermodynamic methods that are most appropriate to his problem.

\section{THERMO DYNAMIC MODELS FOR COMPLEX MIXTURES PRO PERTY CALCULATION}

Models are tools used to describe the physical behaviour of a material system. Depending on the basic knowledge available, these models may be more or less empirical. 
They often contain adjustable parameters that are determined using experimental data.

We don't want to describe all the models used in petroleum engineering thermodynamics, but refer to adequate textbooks for details (Vidal, 2003; Prausnitz et al., 1999). The purpose of this section is to help the reader choose among the many different models that are today available in commercial reservoir and process engineering simulation packages.

Some literature papers provide guidelines in the choice of the best approach for physical properties calculation (see for example Carlson, 1996). A very thorough description of the numerous methods and models for physical property calculations is provided in the well-known book by Poling et al (2001). In this article, as an introduction to the other papers presented in this issue, we will only propose some specific comments that relate to oil, gas and petrochemical applications.

The criteria that the engineer must consider are essentially based on three questions:

- what property is requested?

- what is the temperature-pressure domain?

- what is the fluid composition?

\subsection{What Property is Requested?}

Even though there is a tendency to develop single models that are able to describe all properties (a good test for equations of state is whether they are able to describe correctly all thermodynamic properties by derivation or integration, in particular heat capacities; de Hemptinne et al., 1994), it is often recommended for the practicing engineer to use different methods for different physical properties. In particular, it is recommended to use different methods for the calculation of "single phase properties" (volume as well as enthalpy, entropy and heat capacity) on the one hand, and phase equilibrium on the other hand.

As a general rule, it appears that single phase properties are usually rather well described using the Lee \& Kesler (1975) method (see also Vidal, 2003). This model was tested by de Hemptinne \& Ungerer, 1995 (Fig. 1). Depending on the position of the P-T operating conditions with respect to the fluid phase envelope, a more or less accurate calculation will be obtained. This is done below, using Figure 1. Still more accurate results are found using a BWR-type equation (Benedict et al., 1940). We have tested, as an example, in Figure 2, the Soave version of this

\section{a) Methane}

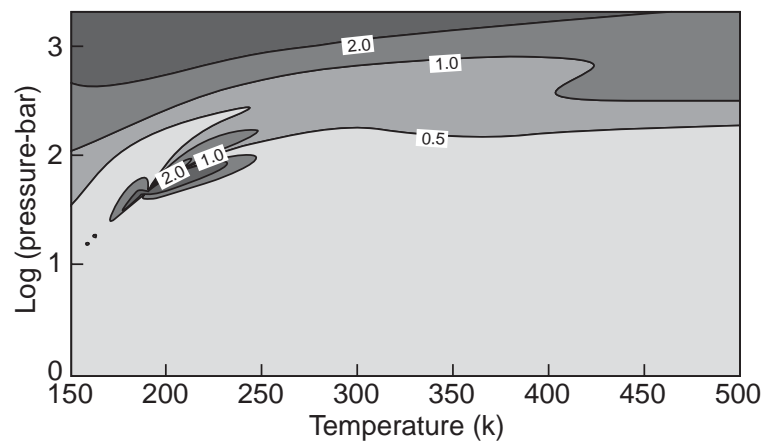

c) Propane

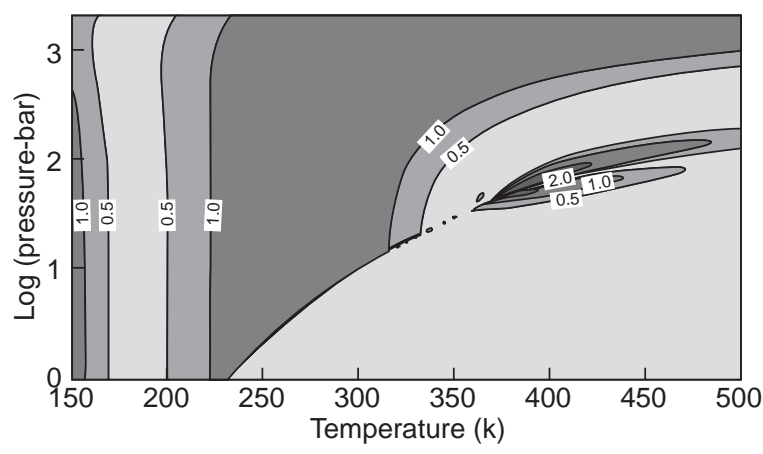

b) Ethane

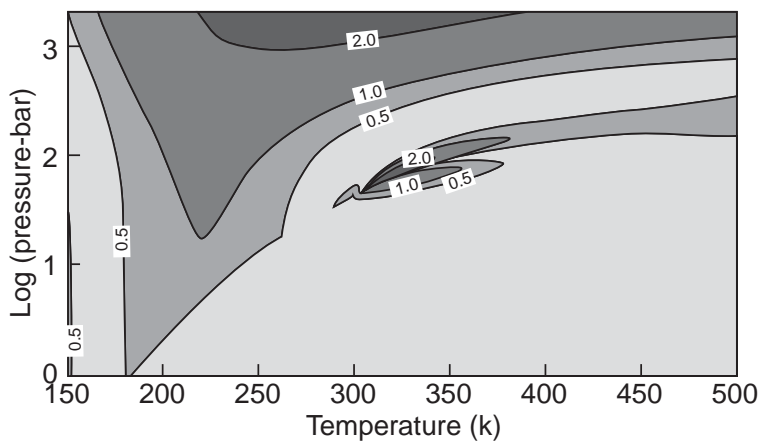

d) $n$-butane

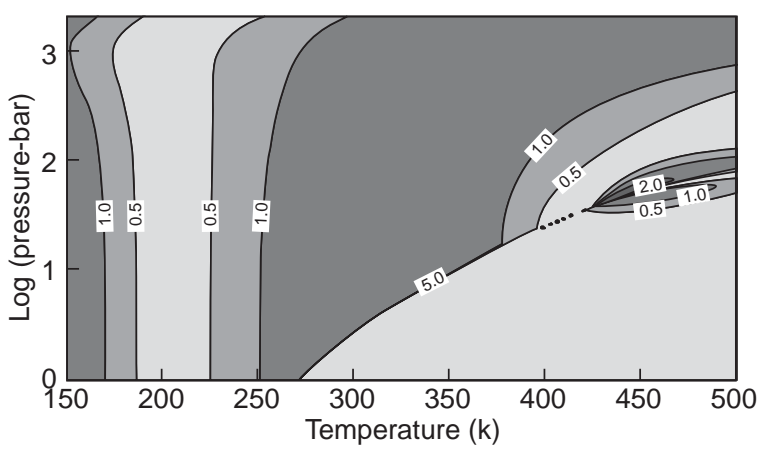

Figure 1

Error maps for the Lee \& Kesler method for molar volume calculation, as taken from de Hemptinne \& Ungerer (1995).Deviations are given in \%. 

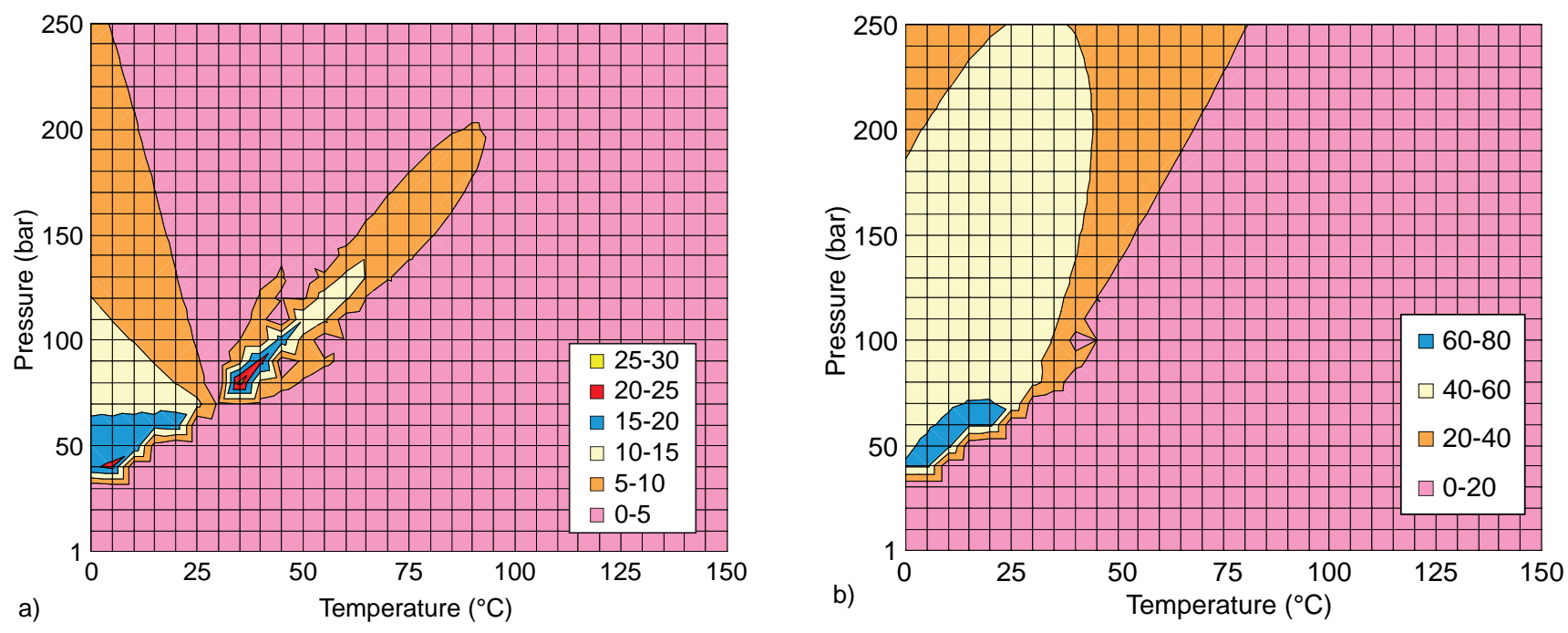

Figure 2

Comparison of two equations of state with the IUPAC data for the isothermal compressibility of $\mathrm{CO}_{2}$ (deviations in \%). Left (a), the SBWR equation of state (Soave, 1995) and right (b) the Peng \& Robinson equation of state.

equation that allows the corresponding states principle to be used (Soave, 1995). The compressibility, a derived property, offers a more stringent test of the eos performance.

When phase equilibrium calculations are performed, the problem is usually more complex, and greatly depends on the composition of the fluid. This is discussed below (Section 1.3.).

\subsection{For Single Phase Properties: What is the Temperature and Pressure Domain?}

A study has been conducted for investigating the accuracy of a number of equations of state as a function of pressure and temperature (de Hemptinne \& Ungerer, 1995) for pure components. It appeared that their accuracy greatly depends on the location of the operating pressure and temperature with respect to the vapour pressure curve of the individual components.

More generally, it is always good to locate on a phase diagram the pressure - temperature conditions in which the physical properties are requested. Such a phase diagram is shown in Figure 3. It indicates the most appropriate model to choose for single phase property calculations.

On the lower right-hand side, for the vapour phase below $0.5 \mathrm{MPa}$, one may consider that the fluid behaves as an ideal gas. This means that no "complex" equation of state is needed. Up to $1.5 \mathrm{MPa}$, a simple Virial correction can be applied to the ideal gas equation of state (Vidal, 2003). Above this pressure, a more complex equation of state is needed. Usually, the Lee \& Kesler (1975) method is considered to be the best (Vidal, 2003). This choice breaks down when approaching the critical zone. Here, still more complex models should be used such as the MBWR eos (Younglove \& Ely, 1987). However, one must always keep in mind that the true description of the near - critical region is not possible using any analytic expression as an equation of state (Levelt-Sengers, 1970).

On the left-hand side of Figure 3, the liquid phase is represented. Because of its low compressibility, the liquid properties are not very sensitive to pressure. Hence, one may state that up to $1.5 \mathrm{MPa}$ above the bubble pressure, the saturation properties can be used as such. Because of the non-idealities characterising some mixtures (mainly when polar components are present), it is necessary to take into account excess properties. The $G^{E}$ models are appropriate for that purpose.

At higher pressures, an adequate equation of state must be used. Once again, the Lee \& Kesler (1975) method is considered to be the best adapted in this area.

Note that the cubic equations of state are generally not well-suited for describing single-phase properties, except when a volume translation is used (Péneloux et al., 1982). Several such translations have been proposed, among which that of Ungerer et al. (1997), that can be extended to hydrocarbon pseudo-components.

\subsection{For Phase Equilibrium Problems: What Fluid Mixture Must be Modelled?}

The arguments developed below are essentially focused on phase equilibrium calculations, where a wrong choice of calculation method may have disastrous consequences on the simulation results. 


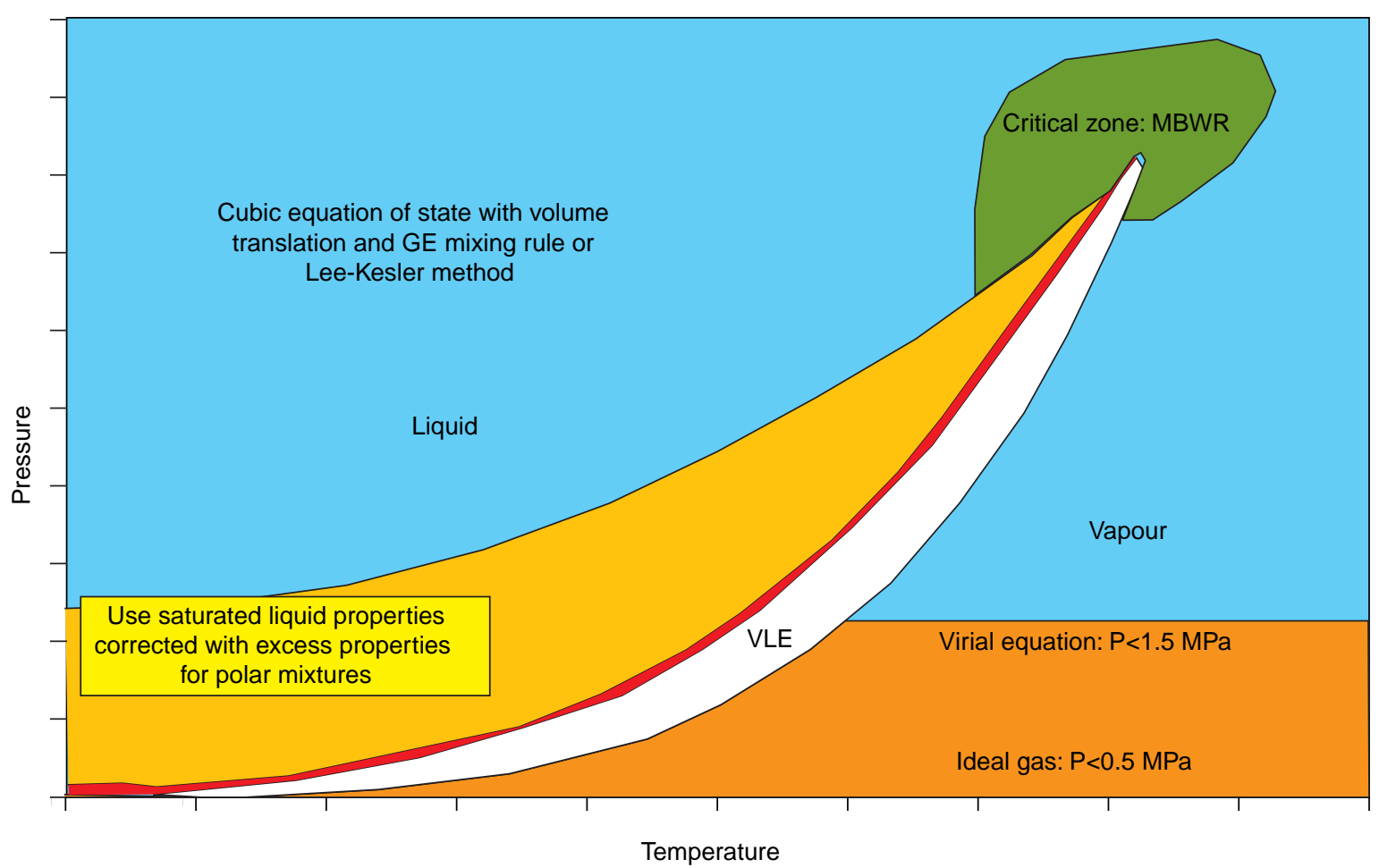

Figure 3

Model selection for single phase property calculations ; the white area is the two-phases liquid - vapour equilibrium domain (see text for explanations).

In what follows, we propose a few decision trees, along with some examples that may be encountered in the petroleum industry.

When pure components are considered, it is always best for the computation of their needed characteristic properties, to use, whenever possible, the correlations provided by internationally-recognized databases (DIPPR, for example). In the case of mixtures, and when the pressure is limited to 1.5 $\mathrm{MPa}$, the heterogeneous method (different models for the liquid and vapour phases) is most appropriate. Table 1 summarizes how the partition (or equilibrium) coefficient is calculated in such a case. At low pressure, below $0.5 \mathrm{MPa}$, the vapour phase can be represented by an ideal gas. For the liquid phase, Raoult's law is both a very simple and powerful method for calculating phase equilibria of mixtures of components belonging to the same chemical family and having relatively close molecular weights. As soon as polar (typically when heteroatoms are present within the hydrocarbon components), or size-related (small and large molecules) interactions appear, an activity coefficient must be used as a correction to the assumption of ideality for the liquid phase.

At higher pressures, the same heterogeneous method can be used, but must be corrected with the pressure effects.
This is shown in Table 1, where a Poynting correction, $\wp_{i}(i, P, T)$ is expressed, along with the fugacity coefficient of the saturated vapour $i, \varphi_{i}^{\sigma}(T)$, and the fugacity coefficient of component $i$ in the gaseous mixture $\varphi_{i}^{V}(\vec{y}, P, T)$.

\section{TABLE 1}

Calculation of the partition (equilibrium) coefficient at moderate pressures (heterogeneous method)

\begin{tabular}{l|l|c}
\hline & $\mathbf{P}<\mathbf{0 . 5} \mathrm{MPa}$ & $\mathbf{0 . 5}<\mathbf{P}<1.5 \mathrm{MPa}$ \\
\hline ideal & $K_{i}=\frac{P_{i}^{\sigma}}{P}$ & $K_{i}=\frac{\wp_{i}(i, P, T) P_{i}^{\sigma}(i, T)}{P} \frac{\varphi_{i}^{\sigma}(T) \gamma_{i}(\vec{x}, T)}{\varphi_{i}^{V}(\vec{y}, P, T)}$ \\
\hline non ideal & $K_{i}=\frac{P_{i}^{\sigma}}{P} \gamma_{i}$ & \\
\hline
\end{tabular}

As an example, we show that the apparently complex water - hydrocarbon heteroazeotropic diagram can be perfectly described using Raoult's law, by assuming no mutual solubility of hydrocarbons and water in the liquid phases (Fig. 5).

When the liquid phase non-ideality must be described accurately, an activity coefficient model (or Excess Gibbs 
energy, $G^{E}$, model) must be used. The choice of which model is best (Fig. 5), depends on two issues:

- What is the degree of non-ideality? Essentially, one can state that hydrocarbon mixtures are generally close to ideal. A regular solution model (Scatchard, 1931) can then be used. If non-ideality results from size differences between molecules, a Flory-type model is better adapted (Flory, 1944). On the opposite, when molecules containing heteroatoms (i.e. other than $\mathrm{H}$ and $\mathrm{C}$ ) are present in significant amounts, a more complex model, such as UNIQUAC (Abrams \& Prausnitz, 1975) or NRTL (Renon \& Prausnitz, 1968) is better. These models usually require many binary parameters. The most complex situation appears with electrolyte solutions. Depending on whether pure water or a mixed solvent is used, the choice will go to the Pitzer (1973) model (many available parameters) or the electrolyte NRTL (Austgen et al., 1989) or UNIQUAC (Nicolaisen, 1993) models.

- What information is available concerning the mixture of interest? Many of the above models require interaction parameters. The more they have, the more accurate they are. However, experimental data must be available as such parameters are to be regressed. Hence, the user must ask himself whether accuracy is important, in which case he must either ask for complementary lab data or use a molecular simulation tool to generate "quasi-experimental data" (these tools remain numerical approximations, but are increasingly accurate and fast). In case accuracy is not essential, he can use group contribution methods, of which the most well-known is UNIFAC (Fredenslund et al., 1975, 1977). This method has been extended to electrolyte mixtures by Li et al. (1994) and Yan et al. (1999).
An application of low pressure non-ideal vapour-liquid equilibria can be found in the design of azeotropic distillation columns.

Gas treatment using alkanolamines is an example where the electrolyte species play a key role in both physical and chemical equilibrium. This is a complex situation, where mixed solvents can be used, that must be handled with the electrolyte activity coefficient methods, as further developed by Barreau et al. in this issue. Austgen et al., 1989, and Kamps, 2005 also provide illustrations on how to describe this kind of equilibrium.

In many industrial situations, the pressure effect on the liquid phase cannot be neglected. The application of homogeneous methods (both phases are described with the same model) based on equations of state (Fig. 6) is increasingly required as the ones that are recently developed allow very good computations, even for highly non-ideal mixtures. The partition (equilibrium) coefficients are here calculated using.

$$
K_{i}=\frac{\varphi_{i}^{L}}{\varphi_{i}^{V}}
$$

Very often, in the petroleum industry, the fluids contain only hydrocarbon (non-polar) components, in which case any cubic equation of state (Vidal, 2003) is well suited to the problem. These equations are rather flexible and provide a number of "tuning" possibilities (as illustrated in Fig. 7):

- The first of these is the temperature dependence of the attraction parameter $(a(T))$. The coefficients in such a relation can be fitted on the vapour pressure of the pure components using expressions as reviewed by Gasem (2001). The best-known equations are those of Soave

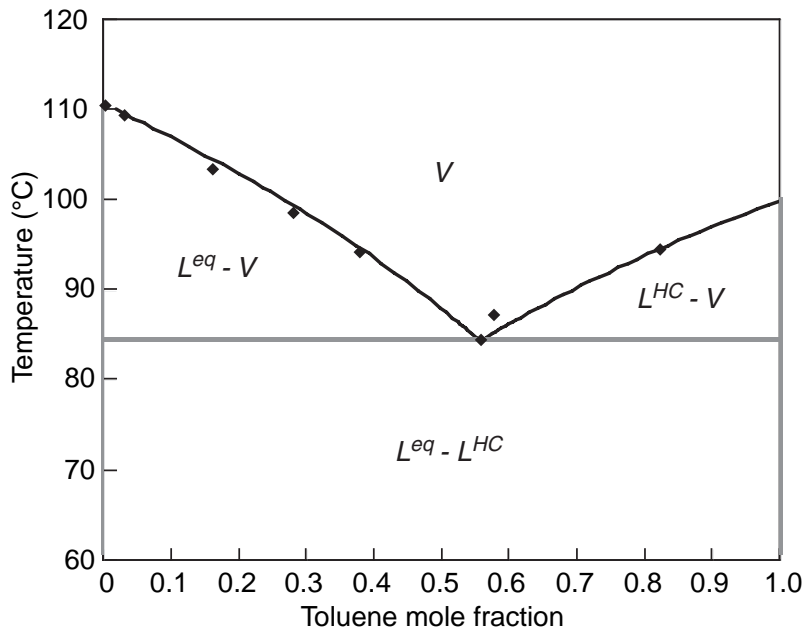

Figure 4

Water - toluene phase diagram at 1 atmosphere, calculated using Raoult's law. Data are from Erlykina et al., 1984.

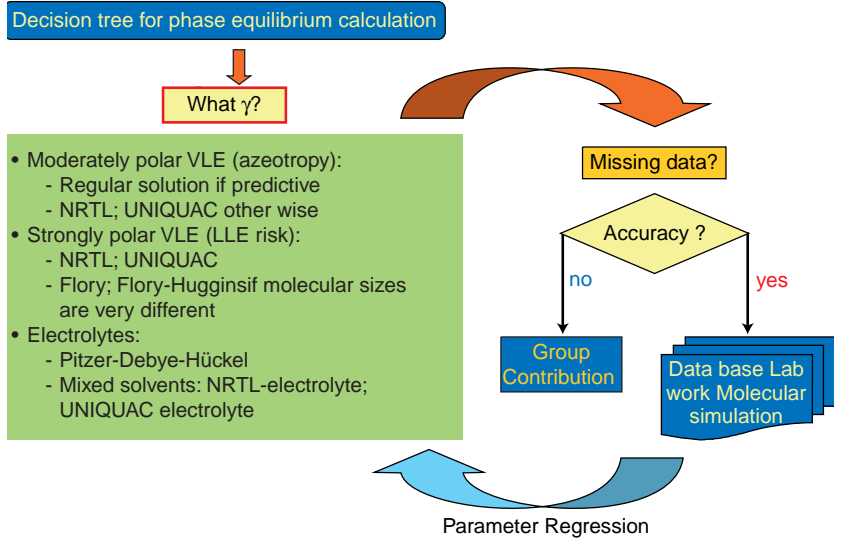

Figure 5

Choice of an activity coefficient model. 


\section{Decision tree for high pressure phase equilibrium calculation}

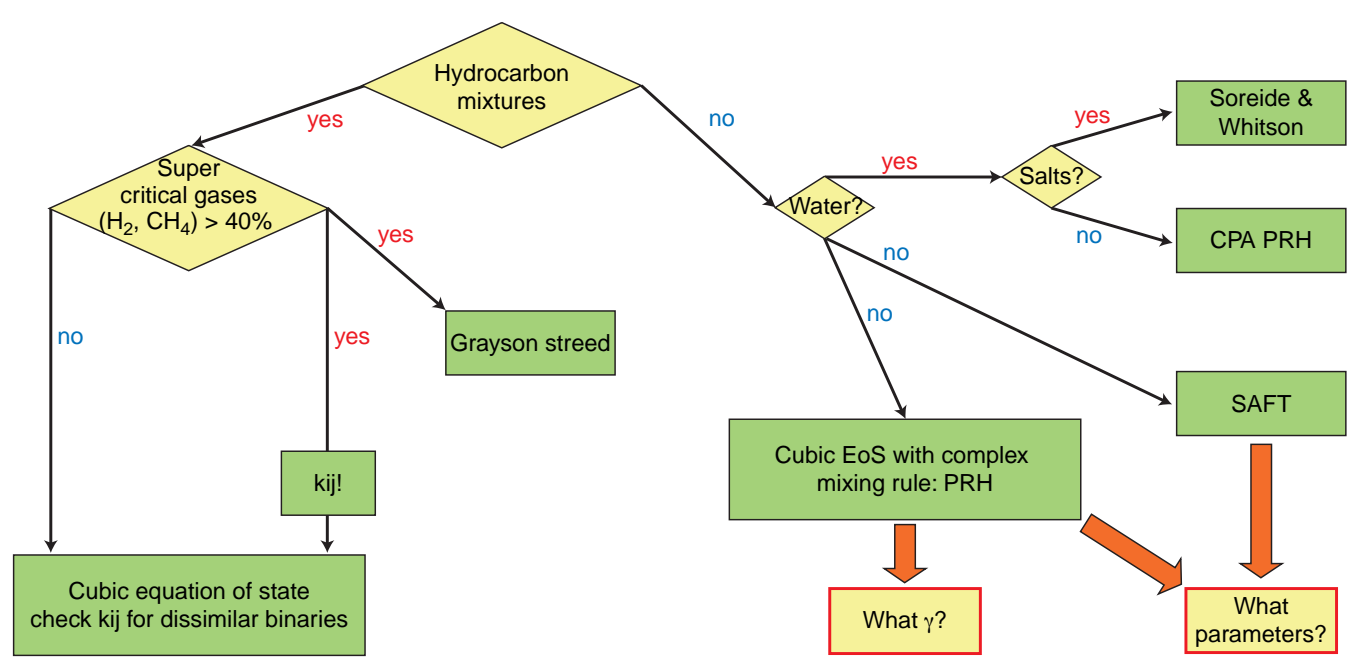

Figure 6

Decision tree in the case of high pressure equilibrium calculation.

(1972), or Mathias \& Copeman (1983). It appears, however, that the expression proposed more recently by Twu (1995) is the best representation of the true behaviour.

- The second tuning possibility appears in the mixing rule for the $a$ parameter. Most often, the use of binary interaction parameters (BIP), often called " $k_{i j}$ ", is wellsuited. For non-polar binaries of similar size, a zero value for this $k_{i j}$ is enough. If experimental mixture data are available, it is better to fit the optimal value of BIP. Some papers have been published proposing correlations, such as the one of Kordas et al. (1995) for methane - heavy hydrocarbons. More recent publications propose a groups contribution method (Jaubert \& Mutelet, 2004, 2005).

Note that the phase separation of asphaltenes containing mixtures may also be described using a cubic equation of state. This approach, which is further described in Pina et al. in this issue, proposes an adequate mixing rule that results in a liquid-liquid phase split when asphaltenes precipitate.

Even though $\mathbf{C O}_{2}$ and $\mathbf{H}_{2} \mathbf{S}$ are not hydrocarbons, there is no harm using a cubic equation of state when the system contains any or both of these components, provided that only liquid- vapour equilibria are calculated. Carroll \& Mather (1995) propose a correlation for the $\mathrm{H}_{2} \mathrm{~S}$ - hydrocarbons BIP, and for $\mathrm{CO}_{2}$ - hydrocarbons, a single value of 0.13 seems to be generally accepted (Valderrama et al, 1988). Figure 8 illustrates this point. Liquid- liquid equilibria may also occur for such mixtures, in which case a more complex mixing rule for the equation of state parameter $a$, such as MHV2 (Michelsen, 1990), should be used.

The presence of large amounts of supercritical gases, such as hydrogen for hydrocracking heavy ends, requires a specific approach. As has been shown by Moysan et al. (1986), the use of a cubic eos induces the need for a large BIP value, that is moreover a function of temperature. Nevertheless, this approach provides a better prediction than the more often used method of Grayson \& Streed (1963).

The problem becomes more complex when strongly polar components are present in non-negligible amounts, and must therefore be taken into consideration in the vapour-liquid equilibrium calculations. The classical $\left(k_{i j}-\right.$ based) mixing rules are no longer sufficient. Huron \& Vidal (1979) developed for that purpose a new family of mixing rules, that combine the advantages of $\mathrm{G}^{\mathrm{E}}$ models (adapted to strongly non-ideal mixtures) and those of equations of state (high pressure and critical point calculations). The principle has since been adapted and improved (Michelsen, 1990; Wong et al., 1992, Boukouvalas et al., 1994). The use of empirical interaction parameters requires, however, an extensive database of binary equilibrium data. If no parameter and no data are available, the PSRK ("Predictive" SRK) method can be of great help (Holderbaum \& Gmehling, 1991). This method uses UNIFAC as a $\mathrm{G}^{\mathrm{E}}$ model, and has since been extensively improved for including gases (Gmehling et al., 1997) and for calculating mixture thermodynamic properties (Chen et al. 2002). As all group contribution methods, it remains, 


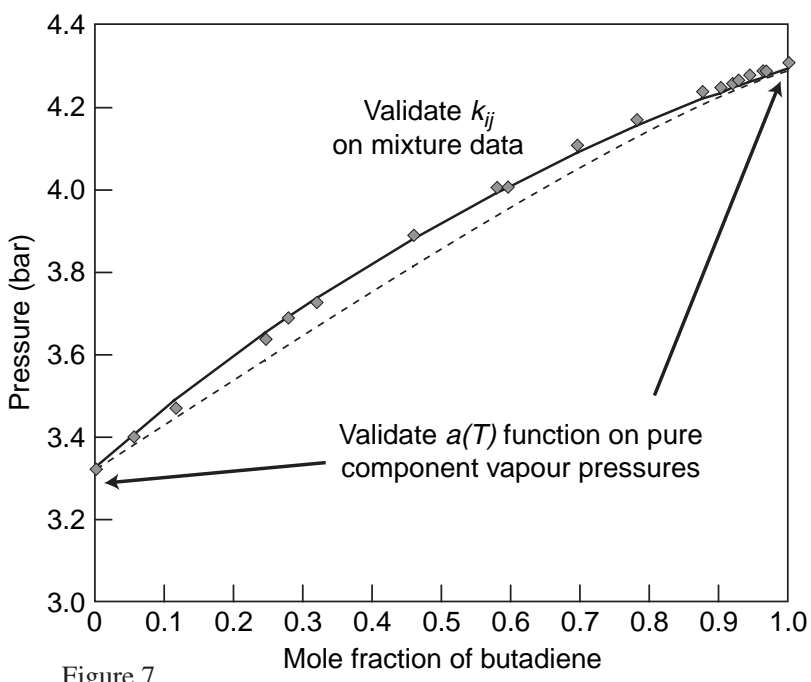

Illustration of the proper use of a cubic equation of state for a hydrocarbon mixture. The example shown is the 1,3-butadiene/1-buten-3-yne mixture at $39.7{ }^{\circ} \mathrm{C}$ (data from Proesk \& Moerke, 1983). First, validate the pure component vapour pressures by fitting the $a(T)$ function; next, fit a binary interaction parameter $\left(k_{i j}\right)$ on the mixture data.

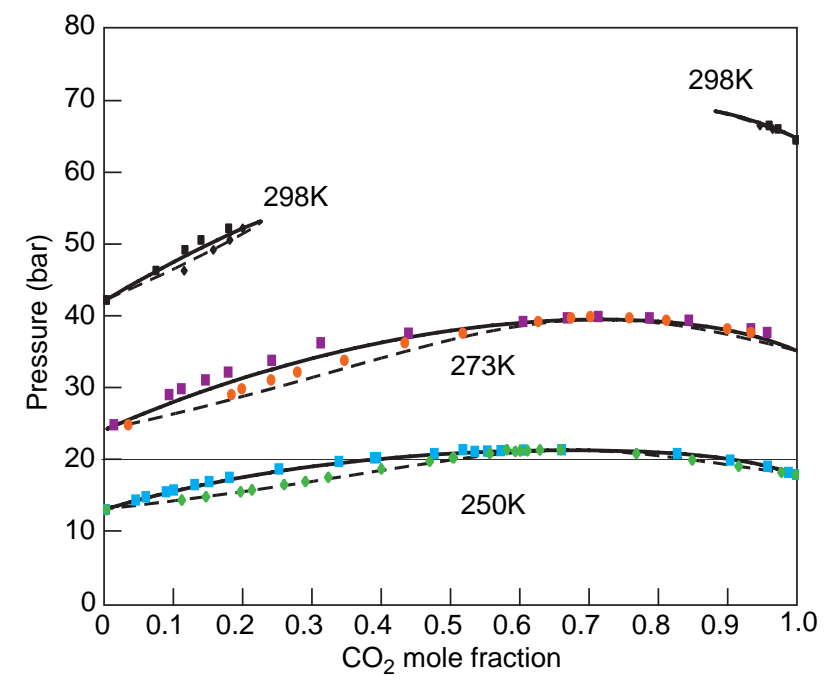

Figure 8

Ethane - Carbon Dioxide mixture, as modelled with the Peng-Robinson eos using $k_{12}=0.13$. Both the azeotrope and the critical points are correctly represented. however, less accurate than using a direct parameter fitting on experimental data.

In the petroleum industry, this non-ideal behaviour can be observed when alcohols (methanol or glycols) are used (often related to the presence of water). At present, the best model that has been identified for this purpose is a cubic equation of state with the Huron - Vidal (1979) mixing rule. An equivalent $G^{E}$-type mixing rule would probably do as well. Adequate interaction parameters must however be determined from the mixture data. As is shown in one of the papers in this issue, the "CPA" equation of state (Cubic Plus Association) has a larger field of applications than the latter with a lesser degree of tuning, as it takes explicitly into account in its formulation the causes of the non-ideality of these systems (associations amongst the mixture components).

The problem becomes still more complex when ionic species are present in the aqueous phase. Liu \& Watanasiri (1999) have published an interesting review for this problem. Equations of state for electrolyte mixtures are presently being developed, but no ready solution exists today in a commercial simulator, except the activity coefficient models with a heterogeneous approach. To our knowledge, the only equation of state that has lead to results for industrial applications is the Soreide \& Whitson (1992) model that adapts the Peng-Robinson eos for treating the case of water-hydrocarbon mixtures in presence of sodium chloride in the water phase.

The case of long chain molecules may also be mentioned (polymers, contrasted fluid mixtures of molecules having large differences in numbers of carbon atoms, etc.). This is where it appears to us that the new SAFT (Chapman et al, 1988, 1990) equation is most promising, as shown later in this issue (de Hemptinne et al.).

\section{COMPOSITIONAL DESCRIPTION}

An important item that has been highlighted in the previous section is that thermodynamic models are essentially physico-chemical equations that include (more or less empirical) parameters. If some guidelines may be given concerning which equation could be preferred, the final computed property greatly depends on the numerical value of these parameters. The latter are partly obtained through a suitable compositional description of the fluid mixtures, which is the topic of this section.

- Accuracy of computed properties is obtained by fitting parameters to accurate data. The physical foundation of the model is of lesser importance than the number of parameters that it contains. The best example of such "accurate" models are the MBWR type (Younglove \& Ely, 1987; Setzman \& Wagner, 1991) equations of state.

- On the opposite, if predictive power is required, we can assume that few or no data exist. Hence, an expression containing too many parameters will be difficult to use because of the lack of physico-chemical background for these parameters. However, the quality of the physical foundation of the models is here essential. Even though their complexity may increase, today's computing 
power can easily overcome this difficulty. As such, both molecular simulation tools, applications of which are provided in this issue, as well as equations of state based on the thermodynamic perturbation theory, also discussed in this issue, are in full development.

We may differentiate here amongst the pure component parameters and the interaction parameters. In most models, only binary interaction parameters are required. However, when dealing with electrolytes, ternary interactions should also be taken into account.

The particularity of petroleum fluids results from the fact that they contain several hundreds of components. Many alternative approaches can be used for describing the physico-chemical behaviour of these complex systems. They are very well reviewed and discussed by Riazi (2005). In some cases, especially in the upstream industry, "black oil" approaches are still employed, reducing the real mixture into a pseudo-binary as we will see later. The refining industry traditionally uses more fractions called "pseudo-components". More and more often, detailed compositional descriptions are available even though few industrial simulators use them. Nevertheless, this is probably the most accurate way to represent complex phenomena, mainly multiphase behaviour when an asphaltenic or a waxy solid deposit occurs.

\subsection{Detailed Compositional Description}

Fluid fossil fuels (crude oils and natural gases) contain hydrocarbons made up of one carbon atom up to more than one hundred carbon atoms. The molecules composing the light end ( $\mathrm{C} 1$ to $\mathrm{C} 10)$ are now well known and their behaviour has been investigated for several decades. However, the number of isomers increases exponentially with the carbon atoms number. Up to $\mathrm{C} 10$, all of the components can now be identified using gas chromatography. From C10 to C20, only the major chemical families (paraffinic, naphtenic and aromatic) can be identified for each carbon atoms number. The physical behaviour of most isomers is not very well documented (i.e. their vapour pressures).

For the evaluation of the characteristic parameters of the (pure and pseudo-) components, the corresponding states principle is a fruitful approach. This principle expresses that the residual thermodynamic (compressibilities, etc.) as well as thermophysical (viscosities, heat conductivities, etc.) properties of any component can be known if its reduced pressure and temperature, as well as acentric factor, are given. This is obviously an oversimplification, but it appears that for hydrocarbon fluids this principle is a powerful approximation.

The characteristic parameters (including the critical parameters required for applying the corresponding states principle) can originate from different sources:

- They can be found in data bases. This is essentially the case for parameters that have a physical significance.
However, all commercial simulators also provide parameter values so that the models proposed can be used with a large variety of components without any additional input from the user. This is very convenient but may be dangerous if the results are used in extrapolation outside the range in which the proposed values have been generated.

- If the molecular formulas of the components are known, group contribution methods can be applied. For the pure component properties, the best known methods are those of Joback (1987) and of Constantinou \& Gani (1994). The former method is rather simple but unable to distinguish among isomers, while the latter adds a second order term that significantly improves the predictions. The most accurate method is that proposed by Marrero \& Gani (2001), but its use is complex. Instead of using the corresponding states principle (whose physical foundation disappears for molecules heavier than C10 as they undergo thermal cracking before reaching their critical point), Coniglio et al, 2000, proposed a groups contribution method that directly provides the cubic eos parameters.

Concerning binary interaction parameters, the UNIFAC (Fredenslund et al., 1975) or the Jaubert (2004, 2005) methods have already been mentioned.

These group contribution methods are not very accurate, but are often sufficient for engineering purposes.

- The best procedure is to fit the needed parameter values on experimental data, even if the two above-mentioned possibilities are available in commercial simulators. In the absence of experimental data, molecular simulation may provide additional information ("quasi-experimental data"). This tool is based on a very fundamental picture of the physical interactions in fluids. Even though it still provides a numerical approximation of reality, one may state that its use becomes more and more easy and its accuracy improves significantly as new algorithms are proposed (see for further discussion Ungerer et al., in this issue).

\subsection{Pseudo-Components Description}

Pseudo-components may be either "lumps" of well-identified components, or a way to describe an unknown mixture of components having close volatility (i.e. a petroleum cut). The calculation of the characteristic parameters are different in both cases. In the former case, the method will depend on the information available. This is generally very different if upstream or downstream applications are considered.

\subsubsection{Lumping and Delumping}

Several approaches exist for lumping a detailed fluid description into a limited number of pseudo-components 
(Ruffier-Meray et al., 1992; Riazi, 2005; Newley \& Merrill, 1991; Soreide, 1989). They generally require two distinct methods:

- Identify a characteristic parameter and the number of lumps that are expected. The characteristic parameter can be a single property (carbon atoms number), or a combination of several ones in which case a "distance" must be defined between the different components. The components then are dispatched among the different lumps according to some algorithm (Montel, 1984).

- The characteristic properties of the lumps are computed on the basis of some averaging rule, based on the properties of the original components (see for example Leibovici, 1993; Neau et al. 1993).

In some cases, it may be important to recover the detailed composition after one or several phase equilibrium calculations have been performed. This is what is called "delumping". This topic has been investigated by Leibovici et al., 2000.

\subsubsection{Upstream Applications}

The procedure for describing a complex fluid by a set of pseudo-components is summarised in a three-steps approach:

- In a first step, the sensitivity of the property to be calculated should be evaluated with respect to the physical information that can be made available through experiments. As an example, a density measurement is generally not enough to calculate a bubble or a dew point. On the other hand, an evaluation of the asphaltene content may provide a good indication of the fluid viscosity (Werner et al., 1996).

- In a second step, experimental data must be gathered, preferably data concerning the property to be modelled (density, bubble or dew point, viscosity, etc.). A typical PVT analysis of a reservoir fluid contains a Constant Composition Expansion (CCE) or a Constant Volume Depletion (CVE) (Savelli et al., 1981, Pedersen et al., 1989). It often comes with a compositional analysis, in order to capture as much as possible detailed information on the physico-chemical characteristics of the individual components that may be present in the petroleum fluid: the number of carbon atoms, the chemical family, the structure of the molecules, etc. The number of pseudo-components that can be used strongly depends on the quality, and on the amount, of data available.

- Finally, the pseudo-components must be given adequate characteristic parameters as input into the model. These parameters are fitted on the experimental data. Often, the characterising parameters are the critical coordinates and the acentric factor $\left(T_{c}, P_{c}, \omega\right)$. In case the amount of data is not sufficient, they can also be determined by a number of correlations (Table 2). In some cases the binary interaction parameter $\left(k_{i j}\right)$ between a light and a heavy component is also fitted.

TABLE 2

Methods for calculating characteristic parameters for petroleum cuts starting from their density and their mean boiling temperature

\begin{tabular}{|c|c|c|c|c|c|c|}
\hline & $\begin{array}{c}\text { Riaizi } \\
\text { et al. } \\
\text { (1998) }\end{array}$ & $\begin{array}{c}\text { Twu } \\
(1984)\end{array}$ & $\begin{array}{l}\text { Cavett } \\
(1964)\end{array}$ & $\begin{array}{c}\text { Lee-Kesler } \\
(1975)\end{array}$ & $\begin{array}{l}\text { Winn } \\
(1952)\end{array}$ & Others \\
\hline$T_{c}$ & $\mathrm{x}$ & $\mathrm{x}$ & $\mathrm{x}$ & $\mathrm{x}$ & $\mathrm{x}$ & \\
\hline$P_{c}$ & $\mathrm{x}$ & $\mathrm{x}$ & $\mathrm{x}$ & $\mathrm{x}$ & $\mathrm{x}$ & \\
\hline$\omega$ & $\mathrm{x}$ & & & $T_{b} / T_{c}>0.8^{*}$ & & $\begin{array}{c}\text { Edmister } \\
(1959)\end{array}$ \\
\hline$Z_{c}$ & $\mathrm{x}$ & $\mathrm{x}$ & & & & $\begin{array}{c}\text { Rackett } \\
(1970)\end{array}$ \\
\hline$M W$ & $\mathrm{x}$ & $\mathrm{x}$ & & $\mathrm{x}$ & & \\
\hline$v^{\operatorname{Liq}}(T)$ & $@ 15^{\circ} \mathrm{C}$ & & $\mathrm{x}$ & & & $\begin{array}{c}\text { Rackett } \\
(1970)\end{array}$ \\
\hline$c_{p}^{\#}(T)$ & & & $\mathrm{x}$ & $\mathrm{x}$ & $\mathrm{x}$ & \\
\hline$P^{\sigma}(T)$ & & & $\mathrm{x}$ & & & \\
\hline
\end{tabular}

* Only for cuts having a reduced normal boiling temperature higher than 0.8 .

\subsubsection{Downstream Applications}

The most difficult property to describe in process simulators is the relative volatility. In that case, the property that should be used for lumping the pseudo components is the vapour pressure. Instead, boiling temperatures at atmospheric or any other pressure are more readily available. The True Boiling Point (TBP) distillation is therefore often employed as an experimental basis for the pseudo-components derivation.

Since the TBP distillation curve is directly related to the volatility of the components included in the petroleum fluid, a simple cut of this curve in a number of pseudocomponents that has been fixed by the user is straightforward. The true challenge lies in the characterisation of the pseudo-components thus created. Often, the only physical properties that identify them are their mean boiling temperature and their density. Empirical correlations are therefore used for determining the characteristic parameters needed for thermodynamic calculations. Table 2 summarises the different methods that exist for this purpose.

\subsection{Black O il Description}

The planning of a "conventional" crude oil production from a reservoir requires the knowledge of the fluid volume, density and viscosity, in addition to its bubble point. At pressures above the latter, the single-phase liquid compressibility is also needed for primary recovery evaluation. The calculation of these properties does not require a very detailed compositional description. 
Considering the large number of calculations needed in basin as well as reservoir simulations, a very simple description is used, based on a two-phases and two-components system. The liquid is the oil, as it is collected from the well, after all the gas has been removed at ambient conditions. The gas is some gaseous pseudo component whose properties and quantity are determined based on very simple PVT tests.

A large number of empirical correlations exist for the determination of the fluid properties based on typical PVT data (McCain, 1990).

\section{MO DEL SELECTION AND COMPOSITIONAL DESCRIPTION IN REGARD WITH THE DOMAIN OF ACTIVITY}

Over time, the number of methods has steadily increased, and the engineer is now faced with a very large choice of methods for his calculations. There is no definite answer on the question regarding the best choice amongst these (Carlson, 1996). Yet, we may suggest some guidelines.

Table 3 shows that depending on the industrial domain and on the available compositional information, the con- straints and the required properties may be very different. Obviously, the model that will be used for responding to some specific needs will have to be selected accordingly.

\section{CONCLUSION}

Even though the basic principles of thermodynamics have been well established for several decades, the practical problems encountered by engineers in modelling the physical properties of real petroleum fluids are not negligible. The reason for this is that no exact set of equations exists for describing the complexity of such natural mixtures. Hence, approximate models are used, the results of which must be continuously verified against experimental data.

This paper provides some general guidelines on thermodynamic modelling of petroleum fluids. It is our hope that it may be of help to the practising engineers, for selecting the appropriate approach that depends very much on the problem to be solved: which property for which mixture, in which pressure - temperature operating conditions ?

What has been emphasized is that thermodynamic models are essentially a combination of several equations

TABLE 3

Summary of the models selection in various oil and gas industry applications

\begin{tabular}{|c|c|c|c|c|c|c|}
\hline $\begin{array}{l}\text { Industrial } \\
\text { application }\end{array}$ & $\begin{array}{l}\text { Available } \\
\text { information }\end{array}$ & $\begin{array}{l}\text { Additional } \\
\text { information }\end{array}$ & $\begin{array}{l}\text { Constraints } \\
\text { information }\end{array}$ & $\begin{array}{l}\text { Properties that must } \\
\text { be calculated }\end{array}$ & $\begin{array}{l}\text { Compositional } \\
\text { description used }\end{array}$ & $\begin{array}{l}\text { Models (eos based) } \\
\text { used }\end{array}$ \\
\hline Basin simulation & $\begin{array}{l}\text { Detailed } \\
\text { compositional } \\
\text { analysis up to C14+ }\end{array}$ & & \multirow{4}{*}{$\begin{array}{l}\text { Very large number } \\
\text { of thermodynamic } \\
\text { calculations. Smooth } \\
\text { variation of property } \\
\text { derivatives vs } \\
\text { operating conditions. }\end{array}$} & \multirow{3}{*}{$\begin{array}{l}\text { Number of phases; } \\
\text { Phases identity, } \\
\text { density and } \\
\text { composition }\end{array}$} & $\begin{array}{l}\text { Lump all } \\
\text { components into a } \\
\text { few (3 to } 15) \text { pseudos }\end{array}$ & $\begin{array}{l}\text { Cubic with classical } \\
\text { mixing rules }\end{array}$ \\
\hline $\begin{array}{l}\text { Reservoir } \\
\text { simulation }\end{array}$ & \multirow{2}{*}{$\begin{array}{l}\text { Detailed } \\
\text { compositional } \\
\text { analysis up to } \mathrm{C} 7+, \\
\text { more rarely up to } \\
\mathrm{C} 21+\end{array}$} & $\begin{array}{l}\text { Stock tank crude } \\
\text { density, } \\
\text { Saturation pressure } \\
\text { (bubble or dew), } \\
\text { CCE, CVD* }\end{array}$ & & & $\begin{array}{l}\text { Lump all } \\
\text { components into a } \\
\text { few ( } 2 \text { to } 4 \text { ) pseudos }\end{array}$ & $\begin{array}{l}\text { Cubic (including } \\
\text { volume shift) with } \\
\text { classical mixing } \\
\text { rules }\end{array}$ \\
\hline $\begin{array}{l}\mathrm{CO}_{2} \text { storage in } \\
\text { depleted oil } \\
\text { reservoirs } \\
\text { simulation }\end{array}$ & & $\begin{array}{l}\text { (Multi-) Phase } \\
\text { behaviour; oil } \\
\text { swelling }\end{array}$ & & & $\begin{array}{l}\text { Lump all } \\
\text { components into } \\
2 \text { pseudos, plus } \mathrm{CO}_{2}\end{array}$ & $\begin{array}{l}\text { Cubic (including } \\
\text { volume shift) with } \\
\text { classical mixing } \\
\text { rules; } \\
\text { Soreide \& Whitson } \\
(1992) \text { for } \mathrm{CO}_{2} \\
\text { solubility in water }\end{array}$ \\
\hline $\begin{array}{l}\text { Transport simulation } \\
\text { (wells, risers, flow- } \\
\text { and pipe- lines) }\end{array}$ & $\begin{array}{l}\text { Detailed } \\
\text { compositional } \\
\text { analysis up to } \mathrm{C} 11+\end{array}$ & $\begin{array}{l}\text { Stock tank crude } \\
\text { density, } \\
\text { Saturation pressure } \\
\text { (bubble or dew), } \\
\text { CCE, CVD* }\end{array}$ & & $\begin{array}{l}\text { Number of phases; } \\
\text { Phases identity, } \\
\text { density, heat } \\
\text { capacity, heat } \\
\text { conductivity and } \\
\text { enthalpy }\end{array}$ & $\begin{array}{l}\text { Lump all } \\
\text { components into a } \\
\text { few }(3 \text { to } 5) \text { pseudos, } \\
\text { plus } \mathrm{H}_{2} \mathrm{O}\end{array}$ & $\begin{array}{l}\text { Cubic (including } \\
\text { volume shift) with } \\
\text { classical mixing } \\
\text { rules }\end{array}$ \\
\hline $\begin{array}{l}\text { Process simulation } \\
\text { (refining or } \\
\text { petrochemistry) }\end{array}$ & $\begin{array}{l}\text { Detailed composition } \\
\text { up to C8 } \\
\text { TBP distillation for } \\
\text { heavier cuts }\end{array}$ & $\begin{array}{l}\text { Gravity for } \\
\text { distillation cuts }\end{array}$ & $\begin{array}{l}\text { Accuracy for a } \\
\text { number of specific } \\
\text { components (traces) } \\
\text { No data for heavy } \\
\text { fractions }\end{array}$ & $\begin{array}{l}\text { Phases composition, } \\
\text { enthalpy, entropy } \\
\text { and heat capacity }\end{array}$ & $\begin{array}{l}\text { Individual for light } \\
\text { components; } \\
30 \text { to } 50 \text { pseudo } \\
\text { components for the } \\
\text { heavy fractions }\end{array}$ & $\begin{array}{l}\text { Many possible, as } \\
\text { explained in the first } \\
\text { section }\end{array}$ \\
\hline
\end{tabular}

* CCE: Constant Composition Expansion; CVD: Constant Volume Depletion. 
that include more or less empirical parameters. Although some guidelines may be given concerning which equations are to be preferred, the final result greatly depends on the value of these parameters. The latter depend firstly on a suitable compositional description of the fluid mixture, as well as on the availability of the characteristic properties for the (pure and pseudo-) components which have thus been selected.

Hence, two challenges lie ahead of us:

- A better understanding of the complex behaviour of petroleum fluids, through well-focused, reliable data acquisition;

- An improved description of the physical foundations of this behaviour in the models that are used.

These challenges are further developed in the other papers of this issue: the two first articles propose a review and additional data concerning two types of systems that remain difficult to model. The first concerns the characterisation of flocculation out of asphaltenic crudes, the second the data analysis of water - alcohol - electrolyte - hydrocarbon mixtures.

The last two papers in this issue indicate the present trends in thermodynamic modelling, whose fundamentals are mainly based on more and more physical principles. Molecular simulation applications are proposed for fluid phase property calculations. A separate article illustrates how these same principles can be used with great success in more conventional equations of state. The models thus become more complex, but thanks to the physical meaning of the parameters, they also become more predictive. The use of such models will allow a much better description of more complex mixtures, including non-hydrocarbon molecules that do not follow the corresponding states principle whose fundamentals date back to Van der Waals (1873).

\section{ACKN O W LEDG EMENTS}

The authors wish to thank their colleagues who participated in the progressive improvement of this paper.

\section{REFEREN CES}

Abrams, D.S. Prausnitz, and J.M. (1975) Statistical thermodynamics of mixtures: a new expression for the Excess Gibbs free energy of partly or completely miscible systems, AICHE. J., 21, 116-128.

Austgen, D.M., Rochelle, T., Peng, X and Chen, CC. (1989) Model of Vapor-Liquid Equilibria for Aqueous Acid Gas - Alkanolamine Systems Using the Electrolyte-NRTL Equation, Ind. Eng. Chem. Res., 28, 1060-1073.

Benedict, M., Webb, G.B. and Rubin, L.C. (1940) J. Chem. Phys., 8, 334 .

Boukouvalas, C., Spiliotis, N., Coutsikos, P., Tzouvaras, N. and Tassios, D. (1994) Prediction of Liquid- vapour equilibrium with the LCVM model: a linear combination of the Vidal and Michelsen mixing rules coupled with the original UNIFAC and the t-mPR equation of state, Fluid Phase equilibria, 92, 75-106.
Carlson, E. (1996) Don't Gamble with Physical Properties for simulation, Chem. Eng. Prog., 10, 35-46.

Carroll, J.J. and Mather, A.E. (1995) A generalized correlation for the Peng-Robinson interaction coefficients for paraffin-hydrogen sulfide binary systems, Fluid Phase Eq., 105, 221-228.

Cavett, R.H. (1964) Physical Data for Distillation Calculation, Vapor-Liquid Equilibria, 27th Midyear meeting, API Division of Refining, San Fransisco, CA, May 151964.

Chapman, W.G., Jackson, G. and Gubbins, K.E. (1988) Phase Equilibria of Associating Fluids : Chain Molecules with Multiple Bonding Sites, Mol. Phy, 65, 1057.

Chapman, W.G., Gubbins K.E., Jackson, G. and Radosz, M. (1990) New Reference equation of state for associating liquids, Ind. Eng. Chem. Res, 29, 1709-1721.

Chen, J. Fischer, K. and Gmehling, J. (2002) Modification of the PSRK mixing rules and results for vapour-liquid equilibria, enthalpy of mixing and activity coefficient at infinite dilution, Fluid Phase Equilibria, 200, 411-429.

Coniglio, L., Trassy, L. and Rauzy, E. (2000) Estimation of Thermophysical Properties of Heavy Hydrocarbons through a group contribution based equation of state, Ind. Eng. Chem. Res., 39, 5037-5048.

Constantinou, L. and Gani R. (1994) New Group Contribution Method for estimating Properties of Pure Compounds, AIChE J. 40, 1697-1710.

de Hemptinne, J.C., Ungerer, P. (1995) Accuracy of the volumetric predictions of some important equations of state, including a modified version of the Lee \& Kesler method, Fluid Phase Eq., 106, 81-109.

de Hemptinne, J.C., Barreau A., Ungerer, P., Behar, E. (1994) Evaluation of Equations of state at high pressure for light hydrocarbons, Proceedings of the 14th International Codata conference, 1822 September.

DIPPR Thermophysical Properties Database, http://www.aiche. org/TechnicalSocieties/DIPPR/index.aspx

Edmister, W.C. and Okamoto, K.K. (1959) Petr. Ref., 38, 8, 117-129.

Erlykina, M.E., Vatskova, V.G., Borisova, I.A., Umanskaya, N.I., Mikhailova, V.A. and Sokolov, N.I. (1984) Dampf-Fluessig Gleichgewicht im System Aceton - Wasser - Toluol bei Atmosphaerendruck, Deposited Doc. Oniitekhim, 1-12.

Flory (1944) Thermodynamics of Heterogeneous Polymers and their solutions, J. Chem. Phys, 12, 425-438.

Fredenslund, Aa, Gmehling, J. and Rasmussen, P. (1977) VapourLiquid Equilibria using UNIFAC, Elsevier, Amsterdam.

Fredenslund, Aa, Jones, R.L. and Prausnitz, J.M. (1975) Group contribution estimation of Activity coefficients in nonideal liquid mixtures, AIChE. J., 27, 1089-1099.

Gasem, K.A.M., Gao, W., Pan, Z., Robinson Jr, R.L. (2001) A modified temperature dependence for the Peng-Robinson equation of state Fluid Phase Equilib. 181 113-125.

Gmehling, J., Li, J. and Fischer, K (1997) Further Development of the SRK model prediction of gas solubilities and vapor-liquid equilibria at low and high pressures. Fluid Phase Equilibria, 141, 113-127.

Grayson, H.G. and Streed, C.W. (1963) Vapor-Liquid Equilibria for high temperature, high pressure hydrogen-hydrocarbon systems, 6th World Congres for Petroleum.

Holderbaum , T. and Gmehling, J. (1991) PSRK: A group contribution equation of state based on UNIFAC Fluid Phase Equilibria 70, 251-265. 
Huron, M.J. and Vidal, J. (1979) New mixing rules in simple equations of state for representing vapour-liquid equilibria of strongly non-ideal mixtures, Fluid Phase Eq., 3, 255-271.

Joback, K. and Reid, R.C. (1987) Estimation of Pure Component Properties from Group Contributions, Chem. Eng. Comm., 57, 233-243.

Jaubert, J.N. and Mutelet (2004) VLE predictions with the Peng-Robinson equation of state and temperature dependent kij calculated through a group contribution method Fluid Phase Equilibria 224, 285-304.

Jaubert, J.N., Vitu S., Mutelet, F. and Corriou, J.P. (2005) Extension of the PPR78 model (predictive 1978, Peng-Robinson EOS with temperature dependent kij calculated through a group contribution method) to systems containing aromatic compounds Fluid Phase Equilibria 237, 193-211.

Kamps (2005) Model for the Gibbs Excess Energy of MixedSolvent (Chemical-Reacting and Gas-Containing) Electrolyte Systems, Ind. Eng. Chem. Res.,44 , 1 , 201-225.

Kordas, A., Magoulas K., Stamakis S., Tassios, D. (1995) Methanehydrocarbon interaction parameters correlation for the PengRobinson and the t-mPR equation of state, Fluid Phase Eq., 112, 33-44.

Lee, B.I. and M.G. Kesler (1975) A generalized Thermodynamic Correlation Based on Three-Parameter Corresponding States, AIChE. J., 21, 3, 510.

Leibovici (1993) A consistent procedure for the estimation of properties associated to lumped systems, Fluid Phase Eq. 87, 189-197.

Leibovici, C.F., Barker, J.W. and Waché, D. (2000) Method for delumping the results of compositional reservoir simulation SPE J. $\mathbf{5}, 227-235$.

Levelt Sengers, J.M.H (1970) "Scaling predictions for thermodynamic anomalies near tha gas-liquid critical point" Ind. Eng. Chem. Fundam., 9, №3, 470-480.

Li , J, Polka, H.M. and Gmehling, J.A. (1994) A GE model for single and mixed solvent electrolyte systems: 1 . Model and Results for strong electrolytes Fluid Phase Eq. 94, 89-114.

Liu, Y. and Watanasiri, S. (1999) Succesfully Simulate Electrolyte Systems, Chem. Eng. Prog., 10, 25-42.

Marrero, J. and Gani, R. (2001) Group Contribution Based Estimation of Pure Component Properties, Fluid Phase Eq., 183, 184-208.

Mathias, P.M. and Copeman, T.W. (1983) Extension of the pengRobinson equation of state to complex mixtures: evaluation of the various forms of the local composition concept, Fluid Phase Eq., 13, 91-108.

McCain (1990) The Properties of Petroleum Fluids, PennWell Publishing Co, Tulsa, OK.

Michelsen, M.L. (1990) A modified Huron-Vidal mixing rule for cubic equations of state, Fluid Phase Eq., 60, 213-219.

Montel, F. and Gouel, P. (1984) A new Lumping Scheme of Analytical Data for Compositional Studies, SPE 13119.

Moysan, J.M. Paradowski, H. and Vidal, J. (1986) Prediction of Phase Behaviour of Gas-Containing systems with cubic equations of state, Chem. Eng. Sci., 41, 8, 2069-2074.

Moysan, J.M., Paradowski, H. and Vidal, J. (1985) Correlation defines phase equilibria for $\mathrm{H} 2, \mathrm{CH} 4$ and $\mathrm{N} 2$ mixes, Hydrocarbon Processing, 73.

Neau, E., Jaubert, J.N. and Rogalski, M. (1993) Characterization of Heavy Oils, Ind. Eng. Chem. Res., 32, 1196-1203.

Newley, T.M.J. and Merrill, R.C. Jr. (1991) Pseudo-component Selection for Compositional Simulation, SPE Reservoir Engineering, 490-496.
Nicolaisen, H., Rasmussen, P. and Sorensen, J.M. (1993) Correlation and Prediction of Mineral Solubilities in the Reciprocal Salt System $(\mathrm{Na}+, \mathrm{K}+)(\mathrm{Cl}-, \mathrm{SO} 4-)-\mathrm{H}_{2} \mathrm{O}$ at $0-100^{\circ} \mathrm{C}$, Chem. Eng. Sci., 48, 18, 3149-3158.

Pedersen, K.S., Fredenslund, Aa and Thomassen, P. (1989) Properties of Oils and Natural Gases, Gulf Publishing Co., Houston, Tx.

Péneloux, A., E. Rauzy and R. Frèze (1982) A consistent correction for Redlich-Kwong-Soave volumes, Fluid Phase Eq., 8, p7-23.

Peng, D.Y. and D.B. Robinson (1976) A new two-constant equation of state, Ind. Eng. Chem. Fundam., 15, 59-64.

Pitzer, K.S. (1995) Thermodynamics, Mc Graw Hill, NY, 3rd edition.

Pitzer, K.S. (1973) Thermodynamics of electrolytes I: Theoretical basis and general equations, J. Phys. Chem.,77, 2, 268-277.

Poling, B.E., Prausnitz, J.M. and O'Conell, J.P. (2001) The properties of Gases and Liquids, Mc Graw Hill, 5th Edition.

Prausnitz, J.M., Lichtenthaler, R.N. and Gomes de Azevedo, E. (1999) Molecular Thermodynamics of Fluid Phase Equilibria, Prentice Hall Int., 3rd edition.

Rackett, H.G. (1970) Equation of state for saturated liquids, J.Chem.Eng.Data, 15, 4, 514-517.

Renon, H. and Prausnitz, J.M. (1968) Local Composition in thermodynamic Excess Functions for Liquid Mixtures, AIChE. J., 14, 135-144.

Riazi, M.R., Al-Sahhaf, T.A. and Al-Shammari, M.A. (1998) A Generalized Method for Estimation of Critical Constants, Fluid Phase Eq., Proceedings of the Eighth International Conference on Properties and Phase Equilibria for Product and Process design.

Riazi, M.R. (2005) Characterization and Properties of Petroleum Fractions, ASTM, January.

Ruffier-Meray V., Barreau, A. and Béhar, E. (1990) Optimal reduction of the analytical data necessary for the thermodynamic characterization of natural gases, SPE 20769, Annual Technical meeting, New Orleans.

Savelli, Labadie, Garcia, Meckler, Murray, Durandeau, Gobinot, Behar and Raynal (1981) Recommandantions pour l'établissement d'un rapport d'étude PVT, Revue de l'IFP, vol 36, n³, 293-307.

Scatchard, G. (1931) Chem. Rev. 8, 321.

Setzmann, U. and Wagner, W. (1991) J. Phys. Chem. Ref. Data, 20, 1061.

Soave, G. (1972) Equilibrium constants for a modified RedlichKwong equation of state,Chem. Eng. Sci, 27, 1197-1203.

Soave, G. (1995) A noncubic Equation of State for the Treatment of Hydrocarbon Fluids at Reservoir Conditions, Ind. Eng. Chem. Res., 34, 3981-3994.

Soave, G. (1999) An effective modification of the Benedict Webb Rubin equation of state,Fluid Phase Eq., 164, 157-172.

Soreide, I. (1989) mproved phase behaviour Prediction of Petroleum Reservoir Fluids from a cubic equation of state, $\mathrm{PhD}$ from the Norwegian Institute of Technology (NTH), Trondheim, Norway.

Soreide, I. and Whitson, C.H. (1992) Peng-Robinson predictions for hydrocarbons, $\mathrm{CO}_{2}, \mathrm{~N} 2$, and $\mathrm{H} 2 \mathrm{~S}$ with pure water and $\mathrm{NaCl}$ brine, Fluid Phase Eq., 77, 217-240.

Twu, C.H. (1984) An internally consistent correlation for predicting the critical properties and molecular weights of petroleum and coaltar liquids, Fluid Phase Eq., 16, 137-150.

Twu, C.H., Coon, J.E. and Cunningham, J.R. (1995) A new generalized alfa function for a cubic equation of state. Part I. PengRobinson equation, Fluid Phase Eq., 105, 49-59. 
Ungerer, P. (1997) Prédiction des propriétés volumétriques des hydrocarures par une translation de volume améliorée Revue de l'Institut Français du Pétrole, 56 n 6, 609-623.

Ungerer, P., Tavitian, B. and Boutin, A. (2005) Applicatioins of Molecular Simulation in the Oil and Gas Industry, Editions TECHNIP.

Valderrama, J.O., Obaid-Ur-Rehman, S. and Cisternas, L.A. (1988) Generalized interaction parameters in cubic equations of state for CO2-nalkane mixtures, Fluid Phase Eq., 40, 217-233.

Van der Waals (1873) The equation of state for gases and liquids, Nobel Lectures in Physics, 1, 254-265, Elsevier, Amsterdam.

Vidal, J. (2003) Thermodynamics: Applications in Chemical Engineering and the Petroleum Industry, Editions Technip.

Werner, A., Behar, F., de Hemptinne, J.C. and Behar, E. (1996) Thermodynamic Properties of Petroleum Fluids during Expulsion and Migration from Source Rocks, Org. Geochem., 24, n 10/11, 1079-1095.
Winn, F.W. (1952) Chem. Eng. Prog. Symposium, 42, 2.

Wong, D.S.H., H. Orbey and Sandler, S.I. (1992) Equation of state mixing rule for nonideal mixtures using available activity coefficient model parameters and that allows extrapolation over large ranges of temperatures and pressures, Ind. Eng. Chem. Res., 31, 2033-2039.

Yan, W., Topphoff, M., Rose, C. and Gmehling, J. (1999) Prediction of vapor-liquid equilibria in mixed solvent electrolyte systems using the group contribution concept Fluid Phase Eq., 162, 97-113.

Younglove, B.A. and Ely, J.F. (1987) Thermophysical properties of fluids ii Methane, Ethane, Propane, Isobutane and Normal Butane, J. Phys. Chem. Ref. Data, 16, 4, 577.

Final manuscript receveid in May 2006

Copyright (C) 2006 Institut français du pétrole

Permission to make digital or hard copies of part or all of this work for personal or classroom use is granted without fee provided that copies are not made or distributed for profit or commercial advantage and that copies bear this notice and the full citation on the first page. Copyrights for components of this work owned by others than IFP must be honored. Abstracting with credit is permitted. To copy otherwise, to republish, to post on servers, or to redistribute to lists, requires prior specific permission and/or a fee: Request permission from Documentation, Institut français du pétrole, fax. +33147527078 , orrevueogst@ifp.fr. 